(RESEARCH ARTICLE)

\title{
Evaluation of two aqueous plant extracts in protection of wheat against phytopathogen fungus, Helminthosporium rostratum
}

\author{
Ashour Eman ${ }^{1,}{ }^{*}$ and Al-Otibi Fatimah ${ }^{2}$ \\ ${ }^{1}$ Department of Microbiology, Faculty of Agriculture, Mansoura University, Mansoura, Egypt. \\ 2 Department of Botany and Microbiology, College of Science, King Saud University, P.O. Box 22452, Riyadh, 11495, \\ Kingdom of Saudi Arabia.
}

Publication history: Received on 29 April 2020; revised on 05 May 2020; accepted on 06 May 2020

Article DOI: https://doi.org/10.30574/wjarr.2020.6.2.0131

\begin{abstract}
In the field and greenhouses, chemical fungicides is the most commonly tool used for controlling fungal disease. Although chemical usage has been very effective in controlling fungal plant diseases, some major problems threaten to limit the continued use of fungicides. In the present research, extracts of Ziziphus and Rumex plants were chosen based on both traditional usages suggestive of antifungal activity. In addition, toxic fungal constituents of higher plants are generally thermo-labile, therefore, an aqueous extract was preferred for prevention any adverse effects. Phytochemicals of both plant extracts were detected by using HPLC, various phenolic and flavonoids compounds were detected. Ziziphus and Rumex extract concentrations that inhibited $50 \%$ of fungal growth (IC 50 ) were 25 and $50 \mathrm{mg} / \mathrm{ml}$, respectively. In vivo, results of morphological parameters of plant growth revealed that aqueous of tested plant extracts had allelopathy effects on seed germination. Increasing of plant roots length was appeared in the case of Ziziphus coated seed (either uninfected or infected). Both Ziziphus and Rumex aqueous extracts had positive synergistic effect where shoot lengths significantly increased. Dry weight of wheat spike significantly increased in Ziziphus and Rumex extracts treatments. Total proteins content of wheat plant were higher in all treatments than infected wheat plant with $H$. rostratum, on contrary, proline content. The results serve and support the new trend in biological control, where the aqueous extracts of Rumex and Ziziphus plants clearly reduced the effectiveness of fungal infection and improved all growth parameters of wheat seedlings (especially in the case of tri-treatments).
\end{abstract}

Keywords: Rumex; Ziziphus; Aqueous extracts; Fungi; Helminthosporium; Antifungal activity

\section{Introduction}

Rumex vesicarius is an edible plant and eaten fresh, or cooked. Green leafy vegetables are good sources of vitamins, minerals, and fibers. Moreover, $R$. vesicarius L. has many important medicinal uses [1]. In addition, Ziziphus spina-christi (L.) is a deciduous tree and native to the warm-temperate and subtropical regions. It has very nutritious fruits and usually eaten fresh. It significantly contributes to the improvement of human health in terms of cure and prevention of diseases [2].

Among the most frequently occurring fungal species in the rhizosphere, Helminthosporium is cosmopolitan fungus found in soils. It causes leaf blight disease of wheat. If infection occurs early in the crop cycle and conditions remain favorable for development, complete defoliation is possible; major reductions in yield and severely shriveled kernels will then results [3]. Control of such diseases mainly depends on fungicidal treatments. However, the use of synthetic fungicides may cause hazards to human health and may directly increase environmental pollution. In addition, some fungicides may not readily be biodegradable and tend to persist for years in the environment. Moreover, some fungal strains have developed resistance to these chemicals.

\footnotetext{
* Corresponding author: Ashour Eman Email: eashour@mans.edu.eg
} 
In addition, wheat, Triticum aestivum, is one of the most important field crops in the Kingdom of Saudi Arabia. Agriculture and Water ministries estimate that 87,280 hectares of wheat will be cultivated, and that production will reach 500,000 MT in 2019/20 [4]. Unfortunately, this crop species was attacked by certain pathogens, especially fungi, in all wheat-growing regions of the Kingdom, which affected its growth and yield.

In recent years, public pressure to reduce the use of synthetic fungicides in agriculture has increased. Concerns have been raised about both the environmental impact and the potential health risk related to the use of these synthetic compounds. Consequently, natural products as plant extracts provide unlimited opportunities for discovering novel antifungal agents of natural origin, high efficacy, restricted toxicity and safety for humans, animals, host plants and ecosystems with low production cost.

Because of these associated problems, researchers are now trying to use environmentally safe alternative methods for fungal control such as biological control or extract of many allelopathic plants.

Plant extracts, especially aqueous, were preferred in the present study for many reasons and referring to the previous researches. Firstly, although much of the antifungal research conducted to date has assessed ethanol or methanol extracts while few studies have utilized aqueous extracts, despite the fact that aqueous extracts a closer approximation of the traditional medicine plants usage.

Most of the researches carried out were based on the use of solvents less polar than water such as hexane, diethyl ether, ethyl acetate, acetone, ethanol and methanol. Therefore, it is not known, from the literature, the extent to which water extracts of various herbs contain valuable bioactive ingredients. However, a water extract was found recently to be richer in polar phenols than acetone, ethanol and methanol extracts of the same plant material [5].

In addition, alcoholic extracts provide a more complete extraction, including less polar compounds, and many of these extracts have been found to possess antifungal properties. However, success with aqueous extracts have been observed [6].

Furthermore, in cases where alcohol extracts have previously shown antifungal potential, should the aqueous extract of the same plant also appear activity it would suggest that the active components might be the more polar compounds. Moreover, polar plant secondary metabolites often rapidly degraded in soil, they generally have no mammalian toxicity, and they can have an effective role in sustainable agriculture [7].

Thus, the present study focused firstly on phytochemical properties of chosen plants to use their aqueous extracts as environmentally safe alternative method for controlling plant pathogenic fungi. Then, the antifungal activity of the aqueous plants extracts against plant pathogenic fungus tested in vitro and apply effective concentration in vivo.

\section{Material and methods}

\subsection{Plant material}

The used plants were Rumex vesicarius L. and Ziziphus spina-christi L. Wild, which collected from Riyadh region, Kingdom of Saudi Arabia.

\subsection{Fungal strain}

Phytopathogenic fungal strain, Helminthosporium rostratum was kindly obtained from College of Food and Agricultural Sciences, King Saud University, Riyadh, King of Saudi Arabia (KSA). Fungal Culture was grown regular by sub-culturing on Czapek Dox agar medium and maintained on PDA slants at $4{ }^{\circ} \mathrm{C}$.

\subsection{Preparation of aqueous plant extracts}

The used plant parts were the leaves from Z. spina-christi and the aerial parts (shoot) from R. vesicarius. Thoroughly cleaned plant materials were shade dried and then collected, as fresh dry plant materials, for usage.

The fresh dry plant materials (both Rumex and Ziziphus) were crushed then $25 \mathrm{~g}$ were soaked in 300 ml distilled water overnight in closed container at room temperature, then transferred on rotary shaker another overnight. The macerates were filtered by gravity twice, first through cotton and then through layers of tissue paper. Finally, the remaining filtrates were left over night in cleaned metallic trays for drying and then collected whole the dried solid materials in 
clean and dry glass container and keep it close in the refrigerator till use. The plant aqueous extract concentrations were prepared as gram per milliliter. The crude aqueous extracts were firstly centrifuged to remove any suspended solid materials, subsequently, was sterilized by filtration using a bacteriological sterile Millipore filter $0.45 \mu \mathrm{m}$ then $0.22 \mu \mathrm{m}$ pore size (Sartorius 18081-E, Satolab RF). Each stock sterile filtered extract was preserved aseptically in refrigerator until needed.

\subsection{Growth inhibition assay}

The agar dilution method described by Sisti et al., [8], with slight modification, was used for determining the inhibition of mycelial growth of tested fungus by both plant extracts. Sterilized aqueous extract was mixed aseptically with molted cooled $\left(40-45^{\circ} \mathrm{C}\right)$ Czapek Dox agar medium, the plates left awhile for solidification. Subsequently, for the bioassay, 6 $\mathrm{mm}$ disc taken from the edge of activity growing colonies of the tested fungal strain was placed in the center of Czapek Dox agar plates that containing specific concentration of plant extract (as treated ) or containing the basal medium only served as a Control. All plates were incubated for 7 days at $25 \pm 2{ }^{\circ} \mathrm{C}$. Each assay was replicated three times. Radical mycelial growth was evaluated by calculating the mean of two perpendicular colony diameters for each replicate. The values were expressed in millimeters diameter and was calculated as percentage of mycelial growth inhibition according to the following formula:

Growth Inhibition $(\%)=\frac{\text { DC-DT }}{\text { DC }} \times 100$

Where: DC= colony diameter of control (untreated), and DT = colony diameter of treated ones [9].

\subsection{Greenhouse experiment}

\subsubsection{Preparation of conidial suspension}

Conidial suspension of tested phytopathogen, Helminthosporium rostratum, was obtained from 10 day-old culture and mixed with sterile distilled water to obtain a homogenous conidial suspension of $10^{6} \mathrm{spore} / \mathrm{ml}$. The fungal inoculum was thoroughly added to the pot soil surface at the rate of $0.5 \%(\mathrm{v} / \mathrm{w})$ per pot, and then covered with a thin layer of sterilized soil.

\subsubsection{Preparation of wheat seeds}

Wheat seeds were surface disinfested in $4 \%$ sodium hypochlorite solution for 10 min and rinsed thoroughly with sterile distilled water. For preparation of infected seeds by $H$. rostratum and plant extract coated seeds, to Petri dishes containing sterilized wheat seeds, conidial suspension and $1 \%$ of aqueous plant extracts were added, respectively, then left to dry and used in sowing. Coated wheat seeds by chemical fungicide (Vitavax) were obtained from National Center for Research on Agriculture and Livestock in Riyadh, KSA.

\subsubsection{The treatments of pot experiment}

The experiment design in a randomized complete block with five replicates of each treatment was carried out in the greenhouse at college of Science, King Saud University. Ten wheat seeds per pot were planted in $15 \mathrm{~cm}$ diameter plastic pots containing $1000 \mathrm{~g}$ sterilized soil. The soil consisted of peat moss and sand in a 1:1 ratio. The moisture content was maintained at 60-70 \% of the soil water holding capacity by continual irrigation with distilled water. All pots were incubated in the greenhouse, five replicates of each treatment.

The treatments of pot experiment were as follows (14 treatments):

\begin{tabular}{ll}
\hline Control (Untreated) & FI + VCS \\
FI (Fungal Infection) & FI + RE \\
VCS (Vitavax Coated Seeds) & FI + ZE \\
RE (Rumex Aqueous Extract) & FI + RCS \\
ZE (Ziziphus Aqueous Extract) & FI + ZCS \\
RCS (Rumex Coated Seeds) & FI + RE + RCS \\
ZCS (Ziziphus Coated Seeds) & FI + ZE + ZCS \\
\hline
\end{tabular}


At the end of the experiment (after eight weeks from planting), the plants were gently picked up and removed adhering soil particles. Some parameters were recorded on the fresh plants, and then the plants were dried at $70{ }^{\circ} \mathrm{C}$ in an aerated oven to constant weight, ground to fine powder and kept for chemical analysis.

Wheat seeds germination (\%) was recorded in pots before picking up the plants. Then, different morphological parameters of plant growth [root length $(\mathrm{cm})$, shoot length $(\mathrm{cm})$, leave number, spike weight $(\mathrm{g})$, plant fresh weight $(\mathrm{g})$, plant dry weight $(\mathrm{g})$ ] were assessed. In addition, biochemical activities of wheat plants (total proteins and the amino acid proline) were determined.

\subsection{Chemical Analysis}

\subsubsection{Total proteins determination}

The total protein contents were measured by using Folin-Ciocalteu reagent according to the procedure by Daughaday et al., [10].

\subsubsection{Proline determination}

Free proline was estimated according to the method described by Bates et al., [11].

\subsubsection{Phytochemical analysis}

Total content of phenolic and flavonoid compounds of the Rumex and Ziziphus plant samples were analyzed according to method of Goupy et al., [12] by using HPLC analysis.

\subsection{Data Analysis}

Statistical analyses of the data were undertaken using STATISTIX 10 computer program (analytical software). The experiments were analyzed by one-way analysis of variance (AVONA) and the significance of the differences between means was calculating using the Duncan test. All values given are means of at least 3 replicates. The results were presented as mean \pm standard error (SE).

\section{Results}

\subsection{Phytochemical Characterization of Plant Extracts}

Data represent in Figure (1) indicate that various phenolic compounds were detected in both plant extracts but qualitatively and quantitatively varied. Catechol, caffeic acid and cinnamic acid were found only in Rumex extract, while coumarin, chrysin and syringic acid were detected in Ziziphus extract only. Salicylic and benzoic content scored highest values (623.54 and $401.99 \mu \mathrm{g} / \mathrm{g}$ respectively) in Rumex extract. Otherwise, ferulic and benzoic acid recorded highest values in Ziziphus extract, 331.48 and $234.67 \mu \mathrm{g} / \mathrm{g}$ respectively.

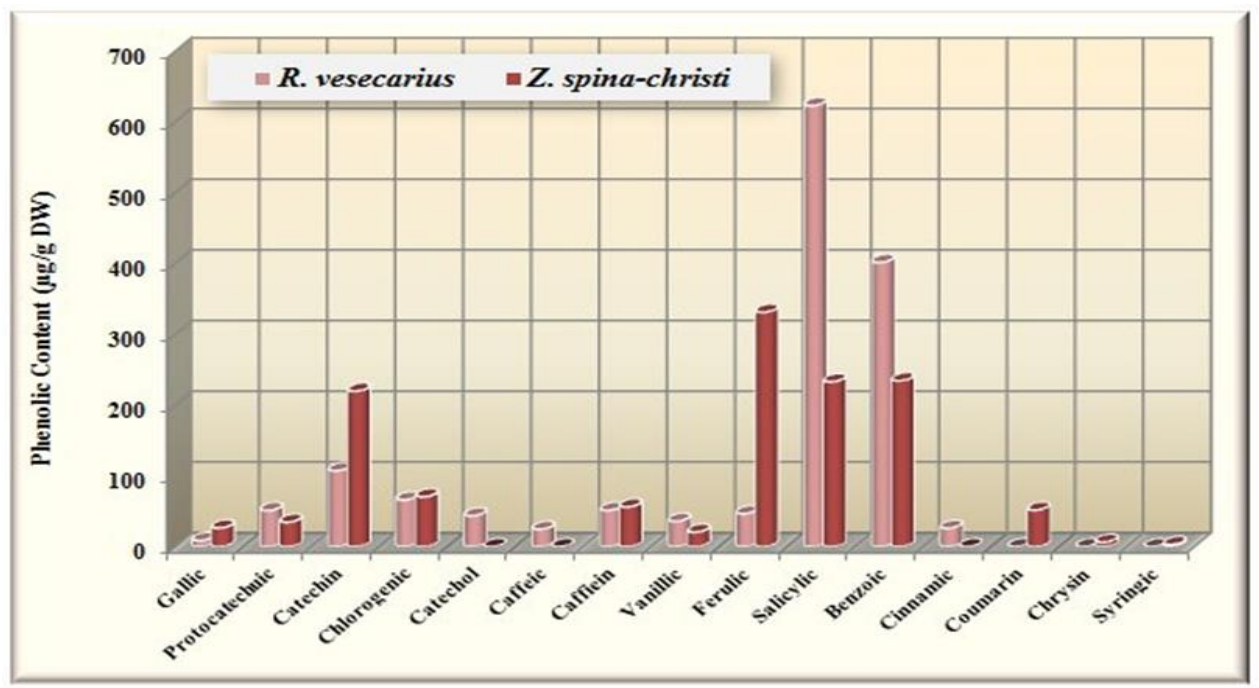

Figure 1 Phenolic compositions $(\mu \mathrm{g} / \mathrm{g})$ of plant extracts 
Among all detected flavonoid compounds, rutin, quericitrin, narenginin and kampferol were detected in both Rumex and Ziziphus plants. Rutin content were reached to 1559.01 and $1069.55 \mu \mathrm{g} / \mathrm{g}$ in Ziziphus and Rumex extract, respectively. In addition, rosmarinic was found only in Rumex and hispertien was detected only in Ziziphus (Figure 2).

Most of the phenolic and flavonoids compounds were detected in both Rumex and Ziziphus extracts. Nevertheless, when consider the total content of flavonoids pattern (its derivatives), Ziziphus spina-christi appeared richer flavonoids where its total contents reached to $2632.91 \mu \mathrm{g} / \mathrm{g}$, mostly two fold its quantity in Rumex vesicarius (1240.15 $\mu \mathrm{g} / \mathrm{g}$ ). However, total phenolic content of both plant species showed a slight variation, where found $1486.98 \mathrm{and} 1288.49 \mu \mathrm{g} / \mathrm{g}$ of $R$. vesicarius and Z. spina-christi, respectively.

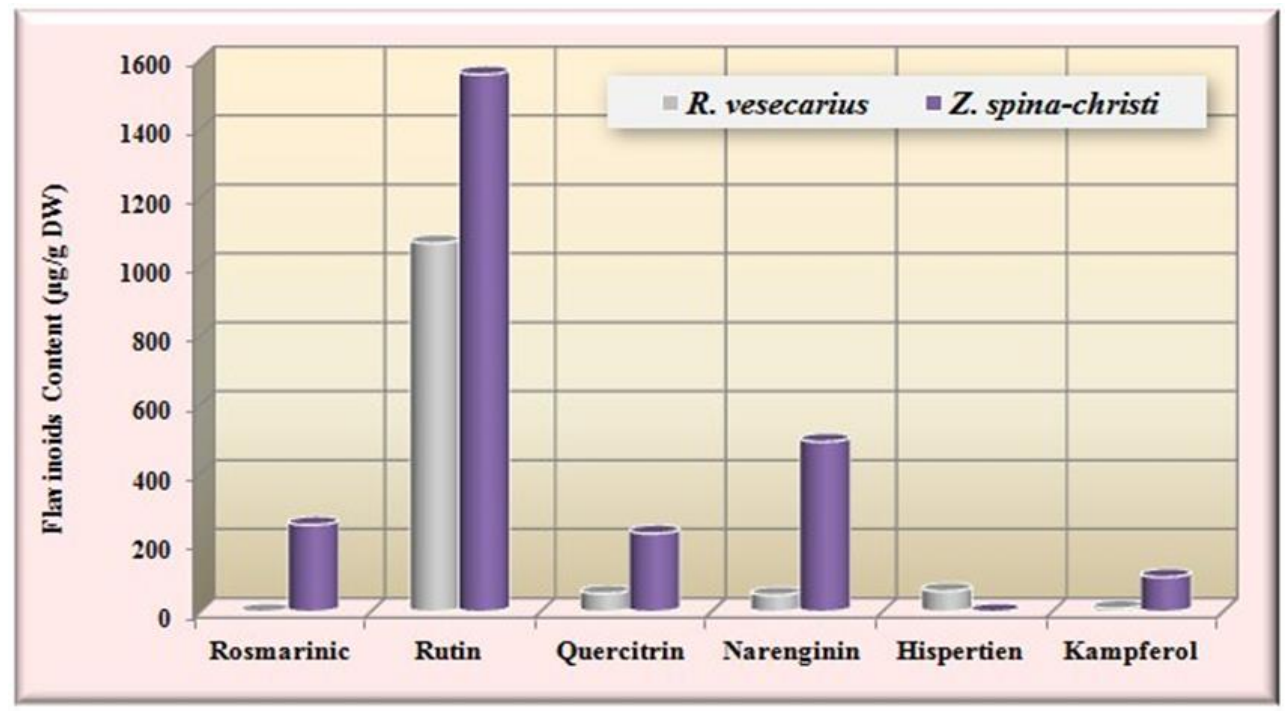

Figure 2 Flavonoid compositions $(\mu \mathrm{g} / \mathrm{g})$ of plant extracts

\subsection{Effect of aqueous plant extracts on fungal growth in vitro}

Antifungal activity of the aqueous extracts of $R$. vesicarius and $Z$. spina-christi at various concentrations $(10,25,50$ $\mathrm{mg} / \mathrm{ml}$ ) was evaluated separately on Czapek Dox agar medium against saprophytic fungus, $H$. rostratum for the possibility of enhancing their application in soil for inhibiting such mycophytopathogen. Data illustrated in Figure (3) reveal that lowest concentration $(10 \mathrm{mg} / \mathrm{ml})$ of Rumex and Ziziphus extract significantly reduced the growth of $H$. rostratum. Then fungal growth obviously decreased by increasing of plant extract concentrations. Rumex and Ziziphus extracts concentration that reduced $\sim 50 \%$ of fungal growth ( IC $_{50}$ ) were 50 and $25 \mathrm{mg} / \mathrm{ml}$, respectively. Ziziphus extract appeared a significant degree of activity higher than Rumex extract against fungal growth.

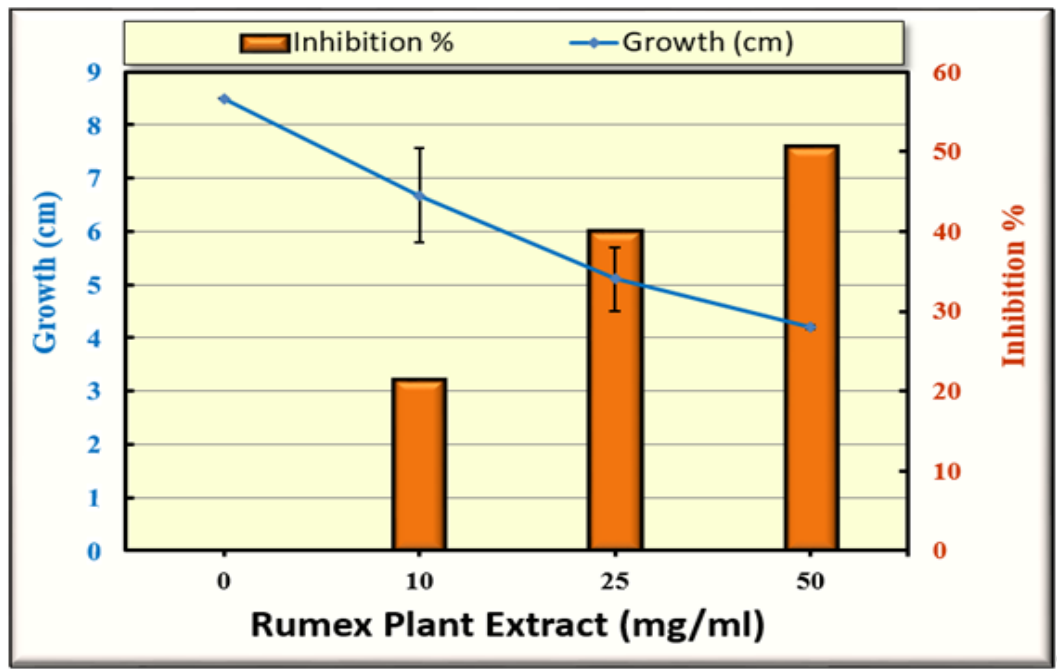




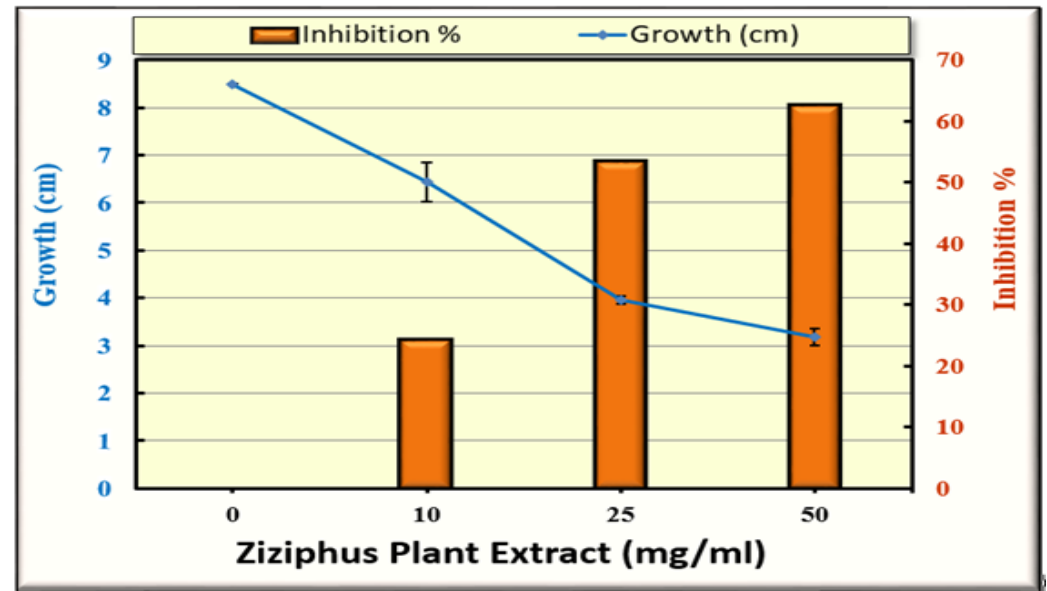

Figure 3 Influence of aqueous plant extracts at various concentrations on mycelial growth diameter (cm) of Helminthosporium rostratum on Czapek Dox agar medium after 7 days of incubation at $25^{\circ} \mathrm{C}$. Data represented as mean \pm standard error.

Aqueous extracts of Rumex and Ziziphus were not only reduced the fungal colony diameter but also caused obvious changes in colony morphotype. The plates of H. rostratum in Figure (4) indicate that fungal hyphae formed very weak and the hyphae grew in the vertical expansion. Colony's color became darker and pigmented comparing to untreated ones.

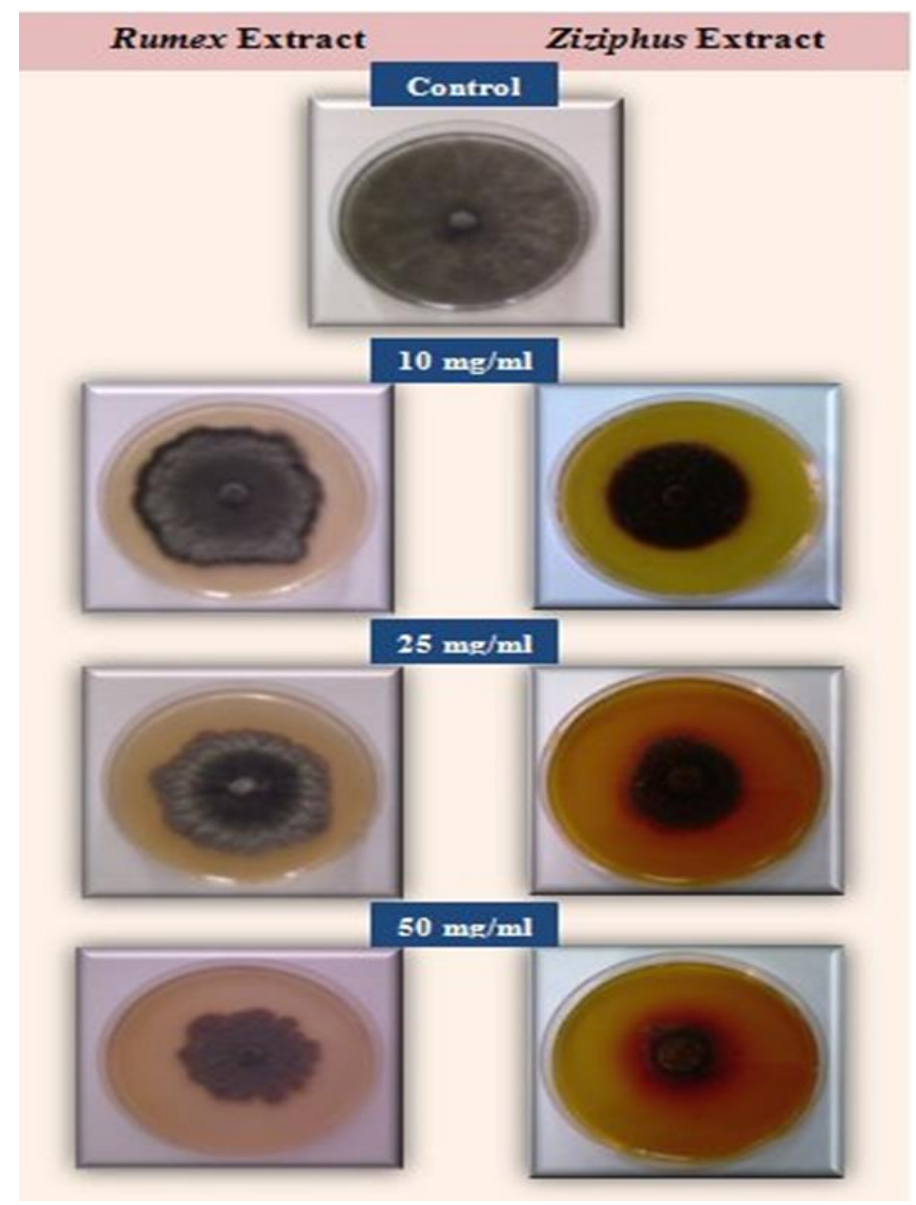

Figure 4 Photographs showing changes in growth of Helminthosporium rostratum in plates of Czapek Dox agar medium amended with different concentrations of aqueous plant extracts. 


\subsection{Antifungal activity of aqueous plant extracts in vivo}

To assess the efficiency of Rumex and Ziziphus aqueous extracts in protection of wheat plant seedlings against plantpathogenic fungus, $H$. rostratum. The experiment designed and conducted in pots under greenhouse conditions for eight weeks with 14 treatments. According to the above obtained results of the most effective concentration of both Rumex and Ziziphus aqueous extracts against $H$. rostratum growth, $50 \mathrm{mg}$ of each aqueous extract (either per pot or for seeds coating or both) and compared with synthetic fungicide-coated (vitavax) wheat seeds.

Data represent in Table (1) show the allelopathy effects of aqueous extracts in pots on seed germination (\%) of wheat plants which was $100 \%$ in the cases of bi-treatment FI+RCS and FI+ZCS. However, seed germination percent was recorded the lowest value (60\%) in the cases of Rumex and Ziziphus extracts treatments (FI+RE \& FI+ZE).

Among all treatment, roots length of wheat plants were significantly varied. Ziziphus coated seed (either uninfected or infected) showed significant high values (17.54 and $17 \mathrm{~cm}$ respectively) comparing with vitavax coated seed (either uninfected or infected) 17.2 and $16.0 \mathrm{~cm}$ respectively. However, all treatments with Rumex aqueous extract of wheat plants caused significantly shorten in roots length.

The shoot lengths of all infected wheat treatments with both Ziziphus and Rumex aqueous extracts were significantly increased comparing with the infected wheat treatment and ranged 16.11-30.37 $\mathrm{cm}$. It obviously found that shoot length of tri-treatments in both cases of Ziziphus (FI+ZE+ZCS) and Rumex (FI+RE+RCS) aqueous extracts were the most effective treatment in the reduction or prevention fungal infection. These results explain that there is a positive synergistic effect for shoot length in the combined treatments against fungal infection.

The impact of fungal infection obviously appeared in lowering leaves number per plant. On contrary, wheat coated seed with vitavax gave highest number of leaves per plant. However, the means values of leaves number for all treatments slightly varied but there were no significant differences.

All the treatments clearly affected in weight of wheat spike and ranged from 0.021 to $0.240 \mathrm{~g}$ (Table 1). Due to fungal infection, wheat spike significantly reduced and gave a lowest value. However, all fungal infection treatments in the presence of both Ziziphus and Rumex extract, spike weight significantly increased.

Data presented in Table (1) show that plant wet weight significantly varied among various treatments. The wet weight of wheat seedling ranged from 0.099 to $0.382 \mathrm{~g}$, about four fold higher. The lowest value recorded in the case of singletreatment of $H$. rostratum infection (FI) while the highest values of seedling wet weight significantly exhibited 0.382 , 0.371 and $0.342 \mathrm{~g}$ in the case of tri-treatment FI+RE+RCS, wheat coated seed with vitavax (VCS) and bi-treatment FI+VCS, respectively. The obtained results of wheat seedling wet weight emphasize that plant extracts' treatments reduced deterioration caused by the fungal infection. Dry weight of wheat seedling' data over all treatments, appear to be more or less in the same trend of the wet weight' data (Table 1).

Data illustrated in Figure (5) show influence of various treatments on protein and proline content of wheat plant in pots experiment. The obtained results revealed that protein content ranged from 3.26 to $1.07 \mathrm{~g} / 100 \mathrm{~g}$ DW. Protein content significantly increased in all treatments comparing with untreated one (control), except case of infected wheat plant with $H$. rostratum (FI), had the lowest protein content value. In contrary, tri-treatment FI+ZE+ZCS was the most effective treatment that significantly scored the highest protein content value. Both Rumex (RE) and Ziziphus (ZE) aqueous extract significantly reduced protein content. However, wheat seed coated with each plant extract (RCS \& ZCS) treatments slight increased protein content. Data also indicated that there was a significant improves in protein content in plant treated or seed coated with chemical fungicide, vitavax. These obtained results explain that there was the positive allelopathic effect for protein content in the combined treatment against fungal infection. In addition, proline content significantly increased in fungal infected plant (FI) and recorded a highest value $3.83 \mathrm{~g} / 100 \mathrm{DW}$. Rumex and Ziziphus aqueous extracts or seed coated led to significant depression in proline content. The lowest value of proline content $(0.64 \mathrm{~g} / 100 \mathrm{~g} \mathrm{DW}$ ) found in tri-treatment FI+ZE+ZCS. The observations of protein and proline imply that certain biochemical alterations in the host might be associated with defense mechanism and enhanced the growth. 
Table 1 Effectiveness of various treatments on growth parameters of wheat plant in pots experiment.

\begin{tabular}{|c|c|c|c|c|c|c|c|}
\hline Treatments & $\begin{array}{l}\text { Germination } \\
(\%)\end{array}$ & $\begin{array}{l}\text { Root Length } \\
\text { (cm) }\end{array}$ & $\begin{array}{l}\text { Shoot Length } \\
\text { (cm) }\end{array}$ & $\begin{array}{l}\text { Leaves } \\
\text { (No.) }\end{array}$ & $\begin{array}{l}\text { Spike Weight } \\
\text { (g) }\end{array}$ & $\begin{array}{l}\text { Plant Wet } \\
\text { Weight (g) }\end{array}$ & $\begin{array}{l}\text { Plant Dry } \\
\text { Weight (g) }\end{array}$ \\
\hline Control & $86^{\text {cde }}$ & $18.80^{\mathrm{a}}$ & $19.28^{\mathrm{f}}$ & $3.83^{b}$ & $0.037^{f g}$ & $0.136^{\mathrm{de}}$ & $0.081^{\text {ef }}$ \\
\hline FI & $92^{\mathrm{abcd}}$ & $14.30^{\mathrm{de}}$ & $16.11^{\mathrm{g}}$ & $3.00^{c}$ & $0.021^{\mathrm{g}}$ & $0.099 \mathrm{e}$ & $0.055^{f}$ \\
\hline VCS & $98^{\mathrm{ab}}$ & $17.20^{\mathrm{b}}$ & $25.11^{b c}$ & $5.17^{\mathrm{a}}$ & $0.130^{\mathrm{b}}$ & $0.371^{\mathrm{a}}$ & $0.180^{\mathrm{ab}}$ \\
\hline $\mathrm{RE}$ & $84^{\mathrm{de}}$ & $13.74 \mathrm{def}$ & $21.36^{\text {def }}$ & $3.83^{b}$ & $0.070^{\mathrm{bcd}}$ & $0.237^{b}$ & $0.159 \mathrm{bcd}$ \\
\hline ZE & $92^{\mathrm{abcd}}$ & $14.22^{\mathrm{de}}$ & $20.88^{\mathrm{ef}}$ & $4.17^{b}$ & $0.039^{\text {efg }}$ & $0.167^{c d}$ & $0.093^{e}$ \\
\hline RCS & $98^{\mathrm{ab}}$ & $14.74^{\text {cde }}$ & $22.57^{\text {cde }}$ & $4.17^{b}$ & $0.028^{\mathrm{fg}}$ & $0.153^{\mathrm{de}}$ & $0.104^{\mathrm{e}}$ \\
\hline ZCS & $98^{\mathrm{ab}}$ & $17.54^{\mathrm{ab}}$ & $21.54 \mathrm{def}$ & $4.00^{\mathrm{b}}$ & $0.034^{\mathrm{fg}}$ & $0.140^{\text {de }}$ & $0.091^{\mathrm{e}}$ \\
\hline $\mathrm{FI}+\mathrm{VCS}$ & $94 \mathrm{abc}$ & $16.00^{\mathrm{bcd}}$ & $25.00^{b c}$ & $3.83^{b}$ & $0.096^{b c}$ & $0.342^{\mathrm{a}}$ & $0.167 \mathrm{abc}$ \\
\hline $\mathrm{FI}+\mathrm{RE}$ & $60^{f}$ & $13.50^{\mathrm{ef}}$ & $20.68^{\mathrm{ef}}$ & $4.00^{\mathrm{b}}$ & $0.059 \mathrm{def}$ & $0.146^{\mathrm{de}}$ & $0.097^{e}$ \\
\hline $\mathrm{FI}+\mathrm{ZE}$ & $60^{f}$ & $13.34 \mathrm{ef}$ & $27.77 \mathrm{ab}$ & $4.00^{\mathrm{b}}$ & $0.073^{\mathrm{cd}}$ & $0.253^{\mathrm{b}}$ & $0.148^{\mathrm{cd}}$ \\
\hline $\mathrm{FI}+\mathrm{RCS}$ & $100^{\mathrm{a}}$ & $14.20^{\mathrm{de}}$ & $24.02^{\mathrm{cd}}$ & $4.00^{\mathrm{b}}$ & $0.040^{\text {efg }}$ & $0.232^{\mathrm{b}}$ & $0.140^{\mathrm{cd}}$ \\
\hline $\mathrm{FI}+\mathrm{ZCS}$ & $100^{a}$ & $17.00^{\mathrm{bc}}$ & 22.99 cde & $4.00^{\mathrm{b}}$ & $0.046^{\text {defg }}$ & $0.225^{\mathrm{ab}}$ & $0.133^{\mathrm{d}}$ \\
\hline $\mathrm{FI}+\mathrm{RE}+\mathrm{RCS}$ & $82^{e}$ & $11.82^{\mathrm{f}}$ & $25.18^{\mathrm{bc}}$ & $3.83^{\mathrm{b}}$ & $0.130^{\mathrm{b}}$ & $0.382^{\mathrm{a}}$ & $0.193^{\mathrm{a}}$ \\
\hline $\mathrm{FI}+\mathrm{ZE}+\mathrm{ZCS}$ & $90^{\text {bcde }}$ & $14.64^{\mathrm{de}}$ & $30.37^{a}$ & $4.00^{\mathrm{b}}$ & $0.240^{\mathrm{a}}$ & $0.269^{b}$ & $0.150^{\mathrm{bcd}}$ \\
\hline
\end{tabular}

Control = untreated; FI = Fungal Infection; VCS = Vitavax Coated Seeds; RE = Rumex Extract; ZE = Ziziphus Extract; RCS = Rumex Coated Seeds and ZCS $=$ Ziziphus Coated Seeds. Means in the same column followed by the same letter are not significantly different based on LSD at $\mathrm{p}=0.05$ according to Duncan's multiple range test. 


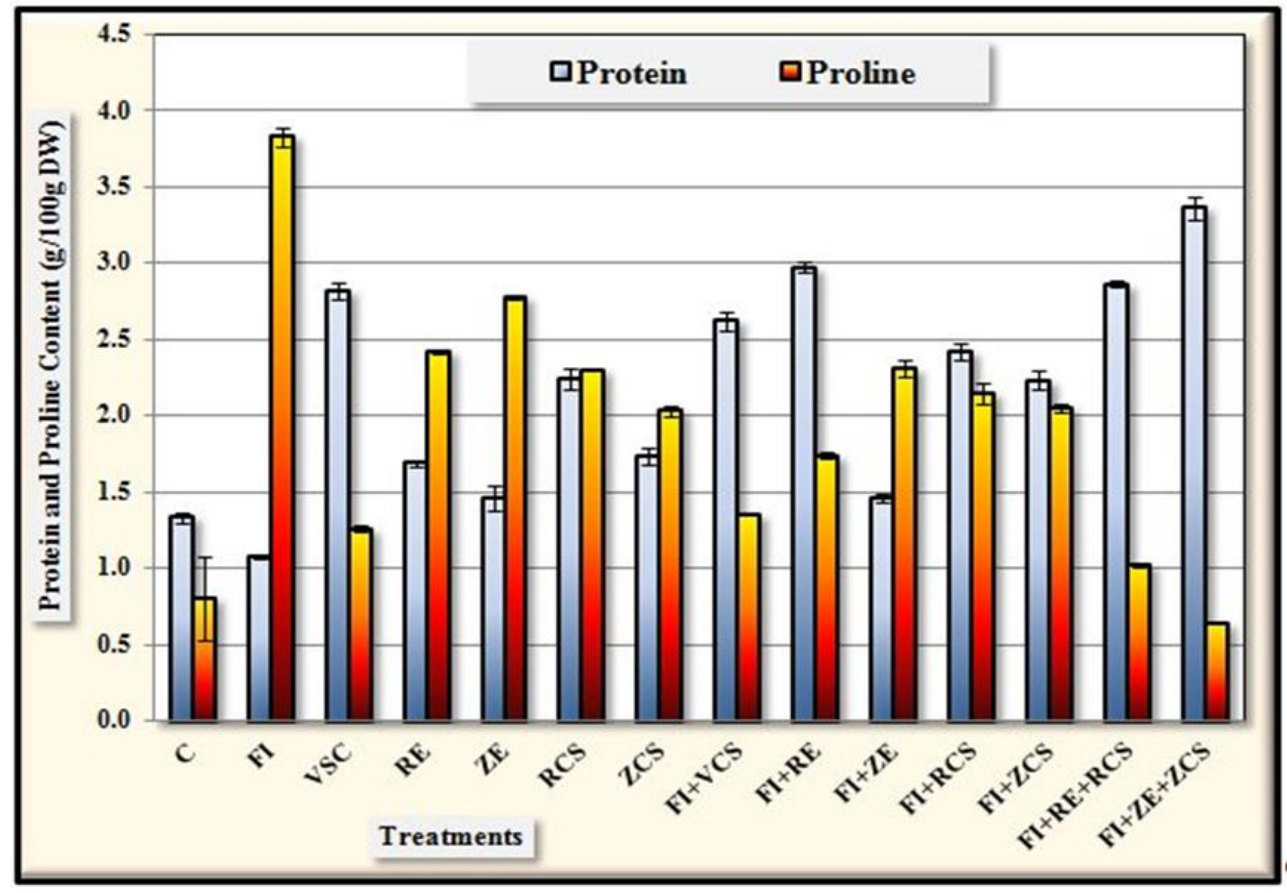

Figure 5 Influence of various treatments on protein and proline content (g/100 g) of wheat plant in pots experiments. Data represented as mean \pm standard error. C, untreated; FI, Fungal Infection; VCS, Vitavax Coated Seeds; RE, Rumex Extract; ZE, Ziziphus Extract; RCS, Rumex Coated Seeds and ZCS, Ziziphus Coated Seeds.

\section{Discussion}

The phytochemicals of Ziziphus and Rumex species revealed that a number of cyclopeptide and alkaloids, flavonoids, terpenoids and their glycosides found in various amounts in this study. The leaves of these plants contain betulinic and ceanothic acids, various flavonoids, saponins, erols, tannins and triterpenes [13-18]. The aqueous extract of $Z$. spinachristi was shown to contain butic acid and ceanothic acid, cyclopeptides, as well as saponins, tannins, glycosides and flavonoids [13]. In addition, Said et al., [15] isolated three compounds from the seeds of Ziziphus spina-christi that identified as $p$-hydroxybenzoic acid, kaempferol, quercetin-3-0- $\alpha$-L-rhamnosyl- $\beta$-D-glucopyranoside (rutin). It also indicated that the Ziziphus' fruits contained high level of total phenolic compounds, $7.55 \mathrm{mg} / \mathrm{g}$ as gallic acid [17]. Moreover, whole Rumex vesicarius L. parts extract found to contain high amount of Quercetin 82.452 $\mu \mathrm{g} / \mathrm{g}$ [16]. Phenolic and antioxidant compounds were detected in leaves and roots of $R$. dentatus, and these compounds are $p$ hydroxybenzoic acid, syringic acid, vanillin, benzoic acid, ferulic acid and cinnamic acid [18].

Phytochemical compounds have a broad-spectrum antifungal activity and mostly are non-toxic to plant and mammalian cells. For instance, plant extract thionins-rich inhibit the growth of about 20 different fungal plant pathogens in vitro [19]. Where their mode of action, thionins are known to form cation-selective ion channels [20] by binding to phosphatidylserine head groups in lipid bilayer membranes [21], which causes permeabilization and oxidative burst followed by cell death [22].

On plates, activity of the aqueous extracts of $R$. vesicarius and Z. spina-christi appeared against growth of saprophytic and plant pathogenic fungus, H. rostratum. The closer articles to the present circumstances as well as in line trend with present data, Haikal [23] who found that aqueous extract of Ziziphus spina-christi was inhibitory to Fusarium growth. In addition, study of Bazaid and Elmougy [24] was evaluated antifungal activity of the leaf juices of Ziziphus in vitro.

Effects of aqueous extracts of varied wild plants against some plant pathogenic microorganisms was observed [25], while, ethanol extract of Ziziphus spina-christi showed no activity against the fungal isolates, Aspergillus niger and Candida albicans [14]. Moreover, the antifungal activity vary with the plants species and material used. This difference in antifungal efficacy is due to the phytochemicals which may also specifically found in certain taxa of plants and vary in presence among different parts of plant tissues [26, 27].

On the other hand, phytochemical analysis of Rumex and Ziziphus indicated above that these plants have sufficient amounts of phenols, phenolic acids and flavonoids (Figs. 1 \& 2). These compounds possess high levels of antimicrobial 
activity; explain their interaction with bio-membrane and serves as plant defense mechanisms against pathogenic microorganisms. Phenolic toxicity to microorganisms is due to the site(s) and number of hydroxyl groups present in the phenolic compound $[28,29]$. Over each, the beneficial antimicrobial effect of plant materials basically results from the secondary metabolites present in the plant and is not usually attributed to a single compound but a combination of these metabolites [30, 31].

Several phytochemical compounds, which have inhibitory effects on microorganisms in vitro, should be undergone in vivo experimentation to assess the efficacy in controlling plant disease comparing to artificial fungicides. In the current study, both aqueous extract of Rumex and Ziziphus showed varying antifungal activities. Therefore, it would be interesting to apply the effective concentration in pot experiments. In pot experiment, the obtained data revealed that all treatments of synthetic fungicide, Vitavax, mostly reduced the pathogenic fungal growth which is reflected on improvement all growth parameters of wheat seedlings. This result is consistent with many literatures, for instance, Sharma-Poudyal et al., [32] found that Vitavax increased germination of wheat seeds and reduced seedling infection by Cochliobolus sativus. Whereas, the use of artificial fungicides is not encouragement because of their costs and harmful effects on the environment. Moreover, chemical fungicide of disease management may lead to the appearance of resistant fungal strains. For these reasons, there is widely recognized that biological control offers suitable alternatives tool for plant disease management [33-35].

The obtained results serve and support the new trend in biological control, where indicated that aqueous extracts of Rumex and Ziziphus clearly reduced the pathogenic fungal growth and improved all growth parameters of wheat seedlings; specially, tri-treatments (FI+RE+RCS \& FI+ZE+ZCS) were the most effective treatments in the reduction or prevention wheat fungal infection.

The observations of protein and proline imply that certain biochemical alterations in the host might be associated with defense mechanism and enhanced the growth. Due to fungal infection, plant seedlings have been stimulated to produce elevated levels of total protein contents in host tissues, which indicated the possibility of involvement of these proteins as a response in the disease defense [36, 37].

Moreover, it has been reported that proline increase proportionately and accumulation faster in plant tissues than other amino acids as a part of the stress signal influencing adaptive responses [38]. That is means accumulation of proline is a common physiological change in plants as response to environmental stress as well as a wide range of biotic and abiotic stresses $[39,40]$.

Many researchers using other fungal species and different plant extracts found similar effects. The studies used plant extract of different species of Rumex against phytopathogenic fungi in vivo have been conducted. Gyung et al., [41] found that Rumex acetocella roots reduced the development of barley powdery mildew caused by Blumeria graminis. In addition, Kim et al., [35] reported that Rumex crispus roots effectively suppressed the development of cucumber powdery mildew caused by Podosphaera xanthii in growth chamber. Haikal [23] evaluated the potential of aqueous extract of Ziziphus spina-christi against the pathogenic fungus Fusarium solani.

Such medicinal plants have therapeutic properties due to biosynthesis of various complex phytochemical substances as phenolic, alkaloids and terpenoids. Synergistic interaction among the multiple phytochemicals may responsible for the overall bioactivity of a given medicinal plant [42].

\section{Conclusion}

The present study aimed to evaluate the antifungal activity of aqueous plant extracts, in hope to find out new natural compounds to be applied as alternative products to synthetic fungicides and develop such types of natural fungicides in biocontrol of many agricultural plant pathogens causing drastic losses to crops. Both plants Rumex vesicarius L. and $Z$. spina-christi are a wild edible plant; cheap and significantly contribute to the improvement of human health in terms of cure and prevention of diseases. Therefore, their extracts serve and suitable to be non-toxic to mammals and their high efficacy for defensing plants against plant myco-pathogens that would make them a good alternative in integrated plant protection, in addition may help in reducing the human health hazard associated with certain synthetic fungicides. 


\section{Compliance with ethical standards}

\section{Acknowledgments}

The authors extend their appreciation to the Deanship of Scientific Research at King Saud University for funding this work through research group No. RG-1441-357.

\section{Disclosure of conflict of interest}

All authors have read and agree to submit this manuscript to World Journal of Advanced Research and Reviews.

\section{Informed consent}

This research does not involve any information about any individual person or group of persons.

\section{Statement of ethical approval}

The present research does not contain any studies performed on animals/humans subjects.

\section{References}

[1] Alfawaz MA. (2006). Chemical composition of hummayd (Rumex vesicarius) grown in Saudi Arabia. Journal of Food Composition and Analysis, 19, 552-555.

[2] Shahat AA, Pieters L, Apers S, Nazeif NM, Abdel-Azim NS, Berghe D and Vlietinck AJ. (2001). Chemical and biological investigations on Zizyphus spina-christi L. Phytotherapy Research, 15(7), 593-597.

[3] Momtaz S, Shamsi S and Dey TK. (2019). Association of Bipolaris and Drechslera species with Bipolaris leaf blight (bplb) infected wheat leaves. J Bangladesh Acad Sci, 43(1), 11-16.

[4] GAIN, Global Agricultural Information Network, Report. (2019). Saudi Arabia Grain and Feed Annual, Pp. 18. (http://agriexchange.apeda.gov.in/MarketReport/Reports/Grain _and_Feed_Annual_Riyadh_Saudi_Arabia_4-42019.pdf)

[5] Triantaphyllou K, Blekas G and Boskou D. (2001). Antioxidative properties of water extracts obtained from herbs of the species Lamiaceae. Intern. J. Food Sci. Nut., 52, 313-317.

[6] Ali-Shtayeh MS and Abu-Ghdeib SI. (1999). Antifungal activity of plant extracts against dermatophytes. Mycoses, $42,665-672$.

[7] Saxena RC. (1983). Naturally occurring pesticides and their potential. In: Shemit, L.W. (Ed.), Chemistry and World Food Suppliers: The Frontiers. Shemrawn II. Pergamon, Press New York, 143-161.

[8] Sisti M, Santi M, Fraternale M, Ninfali P, Scoccianti V and Brandi G. (2008). Antifungal activity of Rubus ulmifolius schott standardized in vitro culture. LWT Food Sc. Technol., 41, 946-950.

[9] Singleton LL, Mihail JD and Rush CM. (1992). Method for research on soil-borne phytopathogenic fungi. The American phytopathology Society St. Paul Minnesota, 265.

[10] Daughaday WH, Lowry OH, Rosebrough NJ and Fields WS. (1952). Determination of cerebrosepiral fluid protein with the folin phenol reagent. J. Lab Clin. Med., 39, 663.

[11] Bates L, Waldren R and Teare I. (1973). Rapid determination of free proline for water-stress studies. Plant and Soil, 39, 205-207.

[12] Goupy P, Hugues M, Boivin P and Amiot JM. (1999). Antioxidant composition and activity of barley (Hordeum vulgare) and malt extracts and of isolated phenolic compounds. J. Sci. Food Agric., 79, 1625-1634.

[13] Adzu B, Amos S, Amizan MB and Gamaniel K. (2003). Evaluation of the antidiarrheal effects of Ziziphus spinachristi stem bark in rats. Acta Trop, 87(2), 245-250.

[14] Abalaka ME, Daniyan SY and Mann A. (2010). Evaluation of the antimicrobial activities of two Ziziphus species (Ziziphus mauritiana L. and Ziziphus spina-christi L.) on some microbial pathogens. African Journal of Pharmacy and Pharmacology, 4(4), 135-139. 
[15] Said A, Huefner A, El Sayed A and Fawzy G. (2010). Isolation and identification of two new cyclic amino acids from the seeds of Ziziphus spina-christi L. (Willd) by means of 1H-NMR, 13C-NMR, HSQC-HMBC and GC-MS. IUFS J. Biol., 69(1), 77-86.

[16] Mostafa HAM, Elbakry AA and Alam EA. (2011). Evaluation of antibacterial and antioxidant activities of different plant parts of Rumex vesicarius l. (Polygonaceae). International Journal of Pharmacy and Pharmaceutical Sciences, 3(2), 109-118.

[17] Yossef HE, Khedr AA and Mahran MZ. (2011). Hepatoprotective activity and antioxidant effects of El Nabka (Zizyphus spina-christi) fruits on rats hepatotoxicity induced by carbon tetrachloride. Nat. Sci., 9(2), 1-7.

[18] Elzaawely AA and Tawata S. (2012). Antioxidant Capacity and Phenolic Content of Rumex dentatus L. Grown in Egypt. J. Crop Sci. Biotech, 15 (1), 59-64.

[19] Molina A, Ahl-Goy P, Fraile A, Sánchez-Monge R and García-Olmedo F. (1993). Inhibition of bacterial and fungal pathogens by thionins of types I and II. Plant Sci., 92, 169-177.

[20] Hughes P, Dennis E, Whitecross M, Llewellyn D and Gage P. (2000). The cytotoxic plant protein, beta-purothionin, forms ion channels in lipid membranes. J. Biol. Chem., 275, 823-827.

[21] Coulon A, Berkane E, Sautereau AM, Urech K, Rouge P and Lopez A. (2002). Mode of membrane interaction of a natural cysteine-rich peptide 3viscotoxin A3. Biochim. Biohys. Acta, 1559, 145-159.

[22] Bussing A, Schaller G and Pfuller U. (1998). Generation of reactive oxygen intermediates (ROI) by the thionins from Viscum album L. Anticancer Res., 18(6A), 4291-4296.

[23] Haikal NZ. (2007). Improving Biological Control of Fusarium Root-rot in Cucumber (Cucumis sativus L.) by Allelopathic Plant Extracts. International Journal of Agriculture \& biology, 9(3), 459-461.

[24] Bazaid SA and Elmougy NS. (2008). Assessment of the bioregulatory activity of the leaf juices of Higher plants in AlTaif, Saudi Arabia against Fusarium solani, Phytophthora spp. and Rhizoctonia solani. Archives of Phytopathology and Plant Protection, 43(11), 1064-1071.

[25] Al-Abeed AS. (1992). Possible antifungal effects of aqueous extracts and residues of some common wild plant species on certain plant. M. Sc. Thesis, University of Jordan, 81

[26] Hadizadeh I, Peivastegan B and Kolahi M. (2009). Antifungal activity of nettle (Urtica dioica), colocynth (Citrullus colocynthis), oleander (Nerium oleander) and konar (Ziziphus spina-christi) extracts on plant pathogenic fungi. Pakistan J. Biological Sciences, 12, 58-63.

[27] Tapwal A, Garg S, Gautam N and Kumar R. (2011). In vitro antifungal potency of plant extracts against five Phytopathogens. Brazilian Arch. Biol. Technol., 54, 1093-1098.

[28] Urs NVRR and Dunleavy JM. (1975). Enhancement of the bactericidal activity of a peroxidase system by phenolic compounds (Xanthomonas phaseoli var. sojensis, soybeans). Phytopathology, 65, 686-690.

[29] Bendini A, Cerretani L, Pizzolante L, Gallina-Toschi T, Guzzo F, Ceoldo S, Marconi AM, Andreetta F and Levi M. (2006). Phenol content related to antioxidant and antimicrobial activities of Passiflora spp. extracts. Eur. Food Res. Technol, 223, 102-109.

[30] Parekh J, Jadeja D and Chanda S. (2005). Efficacy of aqueous and methanol extracts of some medicinal plants for potential antibacterial activity. Turk. J. Biol, 29, 203-210.

[31] Rongai D, Pulcini P, Pesce B and Milano F. (2015). Antifungal activity of some botanical extracts on Fusarium oxysporum. Open Life Sci., 10, 409-416.

[32] Sharma-Poudyal D, Duveiller E and Sharma RC. (2005). Effects of seed treatment and foliar fungicides on Helminthosporium leaf blight and on performance of wheat in warmer growing conditions. J. Phytopathol., 153, 401-408.

[33] Tuber MJ and Baker R. (1988). Every other alternative biological control. Bio. Sci., 38, 660-660.

[34] Klingauf F and Herger G. (1990). Plant defense strategies and their utilization in integrated control. Gesunde Pflanzen, 42, 270-274.

[35] Kim JC, Choi GJ, Lee SW, Kim JS, Chung KY and Cho KY. (2004). Screening extracts of Achyranthes japonica and Rumex crispus for activity against various plant pathogenic fungi and control of powdery mildew. Pest Manag. Sci., 60, 803-808. 
[36] Biswas SK, Srivastava KD, Aggarwal R, Praveen SD and Singh DV. (2003). Biochemical changes in wheat induced by Chaetomium globosum against spot blotch pathogen. Indian Phytopath, 56, 347-379.

[37] Ferreira RB, Monteiro S, Freitas R, Santos CN, Chen Z, Batista LM, Duarte J, Borges A and Teixeira A. (2007). The role of plant defense proteins in fungal pathogenesis. Molecular Plant Pathology, 8(5), 677-700.

[38] Maggio A, Miyazaki S, Veronese P, Fujita T, Ibeas JI, Damsz B, Narasimhan ML, Hasegawa PM, Joly RJ and Bressan RA. (2002). Does proline accumulation play an active role in stress-induced growth reduction? Plant J., 31, 699712.

[39] Verbruggen N and Hermans C. (2008). Proline accumulation in plants: a review. Amino Acids, 35, 753-759.

[40] Szabados L and Savouré A. (2010). Proline: a multifunctional amino acid. Trends Plant Sci., 15(2), 89-97.

[41] Gyung JC, Kyoung SJ, Jin-Seok K, Seon-Woo L, Jun YC, Kwang YC and Jin-Cheol K. (2004). In vivo antifungal activity of 57 plant extracts against six plant pathogenic fungi. Plant Pathology, 20(3), 184-191.

[42] Lattanzio V. (2003). Bioactive polyphenols: their role in quality and storability of fruit and vegetables. J. Appl. Bot. 77, 128-146.

\section{How to cite this article}

Ashour Eman and Al-Otibi Fatimah (2020). Evaluation of two aqueous plant extracts in protection of wheat against phytopathogen fungus, Helminthosporium rostratum. World Journal of Advanced Research and Reviews, 6(2), $139-151$. 